\title{
Programa Escola Ativa, escolas multisseriadas do campo e educação matemática
}

Gelsa Knijnik'

Fernanda Wanderer"

\section{Resumo}

0 artigo discute o Programa Escola Ativa (PEA), uma política pública de âmbito federal endereçada às escolas multisseriadas do campo, enfocando a área da matemática. 0 referencial teórico do estudo consiste em uma perspectiva etnomatemática concebida na interlocução com ideias da obra de maturidade de Wittgenstein e de Foucault. Deste, a principal noção utilizada é a de governamentalidade. 0 material de pesquisa abrange os documentos disponibilizados pelo PEA e questionários respondidos por professores responsáveis pelos cursos de formação no Estado do Rio Grande do Sul. Sua análise mostrou que há um tensionamento entre as orientações pedagógicas oferecidas aos professores e as atividades propostas aos alunos na área da matemática, e que o programa conduz a conduta dos professores, dos alunos e, de modo mais amplo, da população camponesa. Ao regular essa população, ele funciona como um dispositivo de governamento que institui uma visão despolitizada e romântica do campo, trivializa a necessidade de teorização para informar os processos educativos e posiciona a forma de vida camponesa em um patamar inferior ao da forma de vida urbana. Isso se expressa, de modo específico, na educação matemática, sobretudo na geometria: estratégias são postas em ação pelo PEA de modo a reforçar esse processo hierarquizante que é, no limite, um processo (re)produtor de desigualdades. Assim, a população urbana e a do campo acabam por ser significadas não só como diferentes, mas como desiguais.

\section{Palavras-chave}

Programa Escola Ativa - Escolas multisseriadas do campo Educação matemática - Governamentalidade. 


\title{
The Escola Ativa Program, multi-seriated country schools and mathematical education
}

\author{
Gelsa Knijnik' \\ Fernanda Wanderer"
}

\begin{abstract}
The article discusses the Escola Ativa (Active School) Program (EAP), a federal public policy addressed to multi-seriated country schools, which has special focus on the area of mathematics. The theoretical framework for the study consists in an ethnomathematics perspective developed in dialogue with ideas from the later works of Wittgenstein and with those of Foucault. From the latter, the main notion utilized here is that of governmentality. The research material includes documents made available by the EAP and questionnaires filled by teachers responsible for formation courses in the State of Rio Grande do Sul. The analysis discloses a tension between the pedagogical guidelines offered to teachers and the activities proposed to the pupils in the area of mathematics, and also that the program steers the conduct of teachers, pupils and, more broadly, of the local population. By regulating this population, the program works as a government device that institutes a depoliticized and romantic view of the countryside, trivializes the need for theorization in the conception of educative processes, and situates life in the countryside at a level inferior to that of urban life. This is expressed in a more specific way in the mathematical education, particularly in geometry: strategies are put in motion by EAP in order to reinforce this hierarchizing process, which ultimately is a process of (re)production of inequalities. Therefore, the urban and country populations are signified not only as different, but as unequal.
\end{abstract}

\section{Keywords}

Escola Ativa Program - Multi-seriated country schools Mathematical education - Governmentality.

I-Universidade do Vale do Rio dos Sinos,

Porto Alegre, RS, Brazil.

Contact:gelsak@unisinos.br

II-Universidade Federal do Rio Grande do

Sul, Porto Alegre, RS, Brazil.

Contact: fernandawanderer@gmail.com 
Este artigo tem o propósito de discutir uma das políticas públicas educacionais que têm sido implementadas no país em anos recentes. Mais especificamente, examina o Programa Escola Ativa (PEA) - endereçado às escolas multisseriadas do campo -, enfocando a matemática escolar.

Os aportes teóricos que dão sustentação ao estudo encontram-se no campo da etnomatemática, cuja emergência data de meados da década de 1970, a partir das formulações iniciais de Ubiratan D’Ambrosio (1990). Como apresentado em outro estudo (KNIJNIK, 2006b), é vasta a literatura pertinente a esse campo, tanto em âmbito nacional, quanto internacional. Tal literatura destaca a relevância do exame das (etno) matemáticas produzidas pelos mais diversos grupos sociais, sobretudo suas formas de organizar, gerar e disseminar os conhecimentos (matemáticos) presentes em suas culturas.

Desde sua emergência, a etnomatemática vem se constituindo como um campo vasto e heterogêneo, impossibilitando a enunciação de generalizações no que diz respeito aos seus aportes teórico-metodológicos, como mostram os trabalhos de Knijnik (2006a, 2004), Conrado (2005), Ribeiro, Domite e Ferreira (2004) e Pinxten e François (2011), entre outros. Mesmo com essa pluralidade de temáticas, os trabalhos investigativos da área convergem para duas direções: por um lado, possibilitam identificar, reconhecer e valorizar as matemáticas produzidas em diferentes formas de vida; por outro, problematizam a própria linguagem matemática transmitida e ensinada nas universidades e escolas, como demonstram os estudos de D'Ambrosio (2004), Lizcano (2006) e Joseph (1996).

Este artigo embasa-se em uma perspectiva que se insere no conjunto dos trabalhos que vêm conformando o campo da etnomatemática. Tal perspectiva é concebida como uma caixa de ferramentas teóricas advindas da obra de Foucault e das ideias tardias de Wittgenstein, que têm em Investigações filosóficas (WITTGENSTEIN, 2004) sua maior expressão.

Por ser uma política pública, implementada nas diferentes regiões do país; por envolver ações que estabelecem vínculos entre universidades, secretarias de educação estaduais e municipais, assim como escolas multisseriadas; e por disseminar material pedagógico que, por meio dos cursos de formação, é discutido por professores e supervisores das escolas, o PEA tem mobilizado o interesse da comunidade educacional, como apontam os trabalhos de Gonçalves (2009), Matos (2010) e Aragão (2011). Este artigo, devido ao foco na educação matemática e ao tratamento analítico desenvolvido, busca apresentar novas reflexões sobre $o$ até aqui publicado.

0 programa atendia, no início da década de 2010, mais de 10 mil escolas multisseriadas do campo. ${ }^{1}$ Ele abrange um conjunto de ações que envolvem a produção de materiais para alunos e professores, a promoção de cursos de formação continuada aos docentes e a implementação, em cada município participante, de um microcentro que oportunize a criação de grupo de estudos. Os materiais distribuídos às escolas são endereçados aos alunos (cadernos de ensino e aprendizagem de diferentes áreas do currículo escolar) e aos professores (um caderno de orientações pedagógicas para formação de educadoras e educadores - que passaremos a denominar COP - e outros com foco nas diferentes áreas do currículo ${ }^{2}$ ). Além disso, o programa distribui kits com materiais para uso em sala de aula.

Informações disponíveis no Projeto base do PEA (BRASIL, 2010) destacam que o início do programa ocorreu em 1997, com assistência técnica e financeira do Projeto Nordeste (MEC), e com abrangência dos seguintes Estados: Bahia, Pernambuco, Paraíba, Rio Grande do Norte, Ceará, Maranhão e Piauí. Seu objetivo consistia, então, em reduzir a repetência e a evasão, com vistas a elevar as taxas de conclusão dos anos iniciais do ensino fundamental nas áreas

1- 0 Censo Escolar de 2009 indica que, no Brasil, há em torno de 83 mil escolas denominadas rurais, sendo que 39 mil possuem classes multisseriadas, as quais atendem a 1 milhão e 300 mil alunos do ensino fundamental.

2- Neste artigo é examinado somente o Caderno do educador: matemática, indicado ao longo do texto por CEM. 
rurais. Em meados de 1999, com o encerramento do Projeto Nordeste, emerge o Programa Fundo de Fortalecimento da Escola (Programa FNDE ou Fundescola), organizado com recursos do Banco Mundial, que passou a coordenar as ações do PEA (GONÇALVES, 2009). Porém, em meados de 2008, ocorre uma ruptura dos vínculos do programa com essa instituição de financiamento internacional e sua transferência para a Secretaria de Educação Continuada, Alfabetização e Diversidade (SECAD). A partir de então, o PEA passa a se constituir como uma das ações da política nacional de educação do campo.

Críticas ao PEA têm sido formuladas desde o período em que ele esteve vinculado ao Programa Fundescola (GONÇALVES, 2009). Mais recentemente, o programa tem recebido contundentes críticas oriundas dos movimentos sociais e de pesquisadores envolvidos com a educação do campo. ${ }^{3}$ Em convergência com essas reflexões, ao analisar os documentos do PEA, identificamos uma dissonância entre as posições do movimento social Articulação por uma educação do campo (KOLLING; NERY; MOLINA, 1999) - presentes em um grande número de passagens do COP - e as expressas no CEM. Exemplos dessa dissonância são elucidativos. Eis duas passagens em que, de modo bastante claro, percebe-se um alinhamento do PEA com as posições do movimento Articulação por uma educação do campo:

A escola do campo, incluída cada vez mais na agenda das políticas públicas, tem como desafio oferecer educação de qualidade social para todos os povos que vivem nesse e desse espaço. Se a escola do campo mudou é porque o próprio campo está em movimento e é do campo que resultam as reivindicações históricas mais acentuadas pela garantia do direito à vida com dignidade e valorização humana. (BRASIL, 2010f, p. 8)

3- 0 documento Nota técnica sobre o Programa Escola Ativa: uma análise crítica (D'AGOSTINI et al., 2011), elaborado por professores de duas universidades públicas e assinado pelo Fórum Nacional Educação do Campo, sintetiza tais críticas.
[...] a Educação do Campo se diferencia da educação rural, pois é construída por e para os diferentes sujeitos, territórios, práticas sociais e identidades culturais que compõem a diversidade do campo. Ela se apresenta como uma garantia de ampliação das possibilidades de homens e mulheres camponeses criarem e recriarem as condições de existência no campo. Portanto, a educação é uma estratégia importante para transformação da realidade dos homens e das mulheres do campo, em todas as suas dimensões. (p. 16)

São evidentes aí ecos das vozes daqueles que, organizados em movimentos sociais, militam politicamente no âmbito da educação do campo (KOLLING; NERY; MOLINA, 1999). Por outro lado, as orientações pedagógicas do PEA estão radicalmente distantes de qualquer perspectiva que se contraponha à hegemonia da lógica neoliberal, na qual impera o agronegócio, uma lógica que se configura, do ponto de vista social, econômico, político - e também educacional -, na contramão das demandas dos movimentos sociais camponeses.

\section{Referencial teórico do estudo}

A caixa de ferramentas teóricas que, neste estudo, sustenta o exercício analítico empreendido sobre o material de pesquisa está construída com noções advindas das oficinas ${ }^{4}$ de Wittgenstein (que correspondem ao período de maturidade de sua obra) e de Michel Foucault. Temos chamado tal caixa de ferramentas de perspectiva etnomatemática. ${ }^{5}$ Esta possibilita

estudar os discursos eurocêntricos que instituem as matemáticas Acadêmica e Escolar, analisando seus efeitos de verdade

4- 0 uso da expressão "oficinas de Wittgenstein e de Foucault" tem como referência a discussão realizada por Veiga-Neto (2006, p. 80).

5- Estudos como os de Miguel e Vilela (2008) e Knijnik $(2010,2009)$ têm utilizado as ideias da obra de maturidade de Wittgenstein para questionar a noção de uma linguagem matemática universal, possibilitando, com isso, que sejam consideradas diferentes matemáticas, tal como indicado pelo pensamento etnomatemático. 
e examinar os jogos de linguagem que constituem as diferentes matemáticas e suas semelhanças de família. (KNIJNIK, 2012, p. 91)

Assim, podemos problematizar verdades que circulam na esfera da educação matemática, enunciados que estão na ordem do discurso desse campo de conhecimento e que são tomados como inquestionáveis. A perspectiva também oferece elementos para pôr sob suspeição o fato de que os jogos de linguagem que constituem a matemática acadêmica expressariam o conjunto de conhecimentos acumulados pela humanidade, apontando para as relações de poder que acabam por legitimar como única uma forma muito específica de produzir matemática: aquela vinculada ao pensamento urbano, heterossexual, ocidental, branco e masculino. É justamente esse suposto consenso perante o que conta como conhecimento acumulado pela humanidade que a perspectiva etnomatemática possibilita questionar (KNIJNIK, 2004).

Para que se possa garantir a consistência teórica dessa perspectiva (e consequentemente deste artigo, que dela se serve), é preciso apresentar, mesmo que de modo sintético, as noções de Wittgenstein e Foucault escolhidas para sua composição, assim como discutir a pertinência da articulação de duas oficinas oriundas de tradições filosóficas distintas.

As ideias desenvolvidas por Wittgenstein em sua fase de maturidade contêm em seu bojo uma concepção de linguagem não mais com as marcas da universalidade, da perfeição e da ordem, como se preexistisse às ações humanas. Assim como contesta a existência de uma linguagem universal, Wittgenstein problematiza a noção de uma racionalidade total, de um fundamento ontológico para a linguagem. Em vez disso, ele admite a existência de diferentes linguagens que adquirem sentido mediante seus diversos usos. "0 significado de uma palavra é seu uso na linguagem", explicita o filósofo (WITTGENSTEIN, 2004, p. 38). Dessa forma, sendo a significação de uma palavra gerada por seu uso, a possibilidade de essências ou garantias fixas para a linguagem é posta em questão, levando-nos a problematizar também a existência de uma linguagem matemática única e com significados fixos.

Conforme analisado por Knijnik (2012, 2011), com base nas ideias de Wittgenstein, as matemáticas geradas por grupos culturais específicos podem ser entendidas como conjuntos de jogos de linguagem associados a diferentes formas de vida, agregando critérios de racionalidade específicos. Porém, esses diferentes jogos não possuem uma essência invariável que os mantém completamente incomunicáveis uns com os outros, nem uma propriedade comum a todos eles, mas algumas analogias ou parentescos - o que Wittgenstein (2004) denomina semelhanças de família. As ideias apresentadas por Wittgenstein são produtivas para que se problematize o entendimento de uma razão universal e fundacionista que sustenta o pensamento moderno, no qual a matemática ocupa um lugar privilegiado (WALKERDINE, 1995). Essa produtividade interessa sobremaneira à perspectiva etnomatemática. ${ }^{6}$

Ademais, como antes enunciado, a caixa de ferramentas teóricas que compõe essa perspectiva também inclui noções advindas da oficina de Michel Foucault, tais como: discurso, política geral de verdade, governamentalidade e os conceitos que lhe são correlatos. Seu uso, para sustentar teoricamente a discussão aqui empreendida, possibilita-nos considerar a matemática acadêmica, a matemática escolar e o PEA como discursos implicados na produção de relações de poder-saber e na constituição de regimes de verdade. Assim, tais discursos podem ser pensados como constituídos por (ao mesmo tempo em que constituem) uma política geral da verdade (FOUCAULT, 2003), que institui o que funciona como verdadeiro no campo da educação matemática.

6- É importante ressaltar que, como indicam os trabalhos de Gottschalk (2007) e de Miguel e Vilela (2008), o uso do pensamento wittgensteiniano em pesquisas da área da educação tem oferecido originais contribuições para esse campo de estudos. 
Ainda da oficina de Foucault, a ferramenta da governamentalidade se configurou como central para as discussões empreendidas neste artigo. Foi em Segurança, território, população (2008) que o filósofo desenvolveu essa noção em detalhes. A discussão que ele empreende inicia-se com a análise da emergência da população e das formas de poder e regulação que passam a operar sobre ela com o propósito de melhor governá-la.

É nesse ponto que o filósofo introduz o conceito de governamentalidade para abordar as diversas maneiras de governar, destacando

o governo de si mesmo, que pertence à moral; a arte de governar uma família como convém, que pertence à economia; enfım a "ciência de bem governar' o Estado, que pertence à política. (FOUCAULT, 2008, p. 125)

Segundo Fimyar (2009, p. 38), governamentalidade é um neologismo criado por Foucault "ao fundir o governar (gouverner) e a mentalidade (mentalité)", para enfatizar "a interdependência entre o exercício do governamento (práticas) e as mentalidades que sustentam tais práticas". Essa ferramenta da oficina de Foucault nos possibilita estudar como o discurso do PEA opera sobre professores, alunos, gestores das escolas multisseriadas do campo e, no limite, a população camponesa no governo de suas condutas.

A noção de governo é amplamente discutida por Foucault (2008), que aborda os diferentes sentidos que podem ser atribuídos ao uso dessa expressão.

Quanto à noção foucaultiana de governo, ela tem, para expressá-lo de alguma maneira, dois eixos: o governo como relação entre sujeitos e o governo como relação consigo mesmo. (CASTR0, 2009, p. 190).

Este artigo toma como foco o primeiro desses eixos. Estamos interessadas, portanto, em examinar as artes de governar, isto é, a governamentalidade no que tange à condução de condutas. Pesquisas da área da educação como as reunidas no segundo número de 2009 da revista Educação \& Realidade e as que compõem a obra de Saraiva e Santos (2010) - têm utilizado a ferramenta governamentalidade para analisar programas institucionais que atuam sobre a população, mostrando suas técnicas e táticas de governo em relação às condutas dos sujeitos escolares. Nosso estudo está em consonância com esses trabalhos.

Tendo apresentado, mesmo que sucintamente, as ferramentas das oficinas de Wittgenstein e Foucault, impõe-se agora que indiquemos a consistência teórica da articulação dessas duas oficinas na conformação da perspectiva etnomatemática por nós formulada. Inicialmente, é preciso demarcar a posição de Gros e Davidson (2011), que afirmam ser possível identificar em Wittgenstein e Foucault - dois grandes pensadores da linguagem e das formas de vida - mais do que enunciados comuns. Com suas contundentes críticas à filosofia tradicional, ambos tiveram, sobretudo, posturas comuns. A filosofia de Wittgenstein não foi um antecedente necessário para Foucault. Houve, isso sim, uma sintonia entre suas respectivas reflexões, formuladas a partir de tradições de pensamento muito diferentes (PALTRINIERE, 2011). Mesmo assim, o filósofo francês e o austríaco praticam uma filosofia "não-representacionista, não-essencialista, não-fundacionalista" (VEIGA-NETO; LOPES, 2010, p. 34-35), que se afasta dos aspectos formais da linguagem e enfatiza a dimensão estratégica do discurso. Veiga-Neto (2003b, p. 108-109) exemplifica esse ponto nos seguintes termos:

Questões como "não perguntar 'o que é isso'?" mas, sim, "perguntar como isso funciona?", ou "aquilo que está oculto não nos interessa" - que equivale a dar as costas à Metafísica - ou "a verdade é aquilo que dizemos ser verdadeiro" - que equivale a dizer que as verdades não são descobertas pela razão, mas sim inventadas por ela são comuns aos dois filósofos. 
Como argumentamos em outro estudo (KNIJNIK, 2012) e também conforme Bilba (2011) discute em profundidade, os escritos de Foucault a partir de $A$ ordem do discurso têm fortes vínculos com as ideias do período de maturidade de Wittgenstein, expressas em Investigações filosóficas. Tais vínculos ofereceram consistência teórica para articular o pensamento wittgensteiniano e o foucaultino na formulação da perspectiva etnomatemática, que tornou possível não só justificar a existência de jogos de linguagem praticados em diferentes formas de vida e suas semelhanças de família, mas também as relações de poder que posicionam, diferentemente, esses distintos jogos e, por consequência, seus praticantes.

\section{Metodologia}

0 material de pesquisa escrutinado neste artigo abrange os documentos disponibilizados pelo PEA, em especial aqueles da área da matemática, e um conjunto de 150 questionários que foram respondidos individualmente por professores responsáveis pelos cursos de formação desenvolvidos nos diferentes microcentros do PEA no Estado do Rio Grande do Sul. 0 questionário envolveu cinco questões dissertativas que abordavam as relações entre o trabalho docente em escolas multisseriadas, a forma de vida do campo e o processo de ensino-aprendizagem da matemática escolar, particularmente na área de geometria. 0 preenchimento do questionário ocorreu no início de uma das seis etapas da capacitação docente realizada pelos coordenadores do PEA no Rio Grande do Sul.

Os documentos do PEA, sobretudo aqueles da área da matemática, foram tomados como parte do material empírico escrutinado. Ao examiná-los, não tivemos o propósito de verificar se eles são mesmo utilizados nas escolas multisseriadas ou se suas orientações e prescrições são seguidas pelos docentes. Acompanhando Bujes (2009, p. 273), os documentos aqui analisados foram considerados artefatos que servem como guias para a conduta, instrumentos para governar os modos pelos quais as professoras e adicionalmente as famílias são instadas a levar a bom termo o processo formativo de crianças e jovens.

Algumas estratégias de governo das condutas dos docentes se fazem presentes nos documentos do PEA. As orientações pedagógicas são apresentadas de modo detalhado, abrangendo não só o conteúdo a ser ensinado, como também os procedimentos didáticos a serem seguidos. No CEM (BRASIL, 2010g) é dito até mesmo como os alunos devem ser organizados em aula: há atividades a serem desenvolvidas em duplas de alunos, que são justificadas por favorecerem uma interação propícia à aprendizagem. Mas não se trata de formar quaisquer duplas. Fazendo referência ao pensamento de Vygotsky, há a recomendação explícita de "coloca[r] um aluno com bom desempenho junto com outro mais lento ou que tenha dificuldades", pois

aquilo que uma criança não é capaz de fazer sozinha poderá desempenhá-lo com a ajuda de outro (adulto ou alguém mais adiantado que ela). E um colega com melhor desempenho consegue realizar boas intervenções quando trabalha em companhia de outro. (BRASIL, 2010g, p. 6)

Para “enriquecer sua aula” é

aconselha[do] ao professor sempre ler as atividades iniciais no livro do aluno e consultar o manual do professor na busca de subsídios para enriquecer sua aula. (p. 4)

As aprendizagens efetuadas pelos alunos na escola devem, ademais, ser estendidas às suas famílias. Podemos inferir, então, que a conduta dos professores é dirigida para que as aprendizagens de seus alunos ocorram dentro de uma racionalidade específica. Mas não só a população infantil é atingida pelo governo do 
PEA, "pelos mecanismos, táticas, saberes, técnicas e instrumentos destinados a dirigir a conduta d[as] [crianças]" (GADELHA, 2009, p. 120). Ao fim e ao cabo, toda a comunidade acaba sendo assujeitada a esse governo.

0 exercício analítico apoiou-se nas formulações do discurso de inspiração foucaultiana, conforme discutido por Duarte (2009) e Silva (2011). Isso implicou considerar o dito em sua exterioridade, mantendo-nos vigilantes para nos afastarmos de uma posição valorativa e da busca por explicações sobre o que estaria oculto no material analisado. Tomamos a precaução de não perguntar pela lógica interna das enunciações presentes no material de pesquisa. Ao contrário, a análise teve como foco destacar a recorrência das enunciações, organizando séries a partir delas e verificando as rupturas e as continuidades/descontinuidades que mantinham entre si.

\section{O PEA como arte de governar}

0 exercício analítico realizado evidenciou que, como política pública, o PEA conduz a conduta de professores, de alunos e da comunidade vinculada às escolas multisseriadas que dele participam, constituindo-se em um dispositivo (no sentido concebido por Michel Foucault) de governamento que obscurece as fronteiras entre as formas de vida urbanas e do campo, mas hierarquiza tais formas de vida, posicionando a urbana como superior.

No exame dos questionários, constatamos que escolas do campo estavam situadas em comunidades que podem ser pensadas como contemplando o obscurecimento de fronteiras indicado. Seus alunos eram "filhos de agricultores", muitos deles trabalhando "em fábricas do município, como curtume e calçados". Mesmo aqueles "que trabalha[va]m na lavoura, juntamente com seus pais, possu[ía]m grande atração pelo que é da cidade”. Contribuir com o trabalho dos adultos implicava, muitas vezes, a ausência às aulas. Essa contribuição era "naturalizada" pelos professores, que recorrentemente se referiam às crianças como tendo "enorme potencial para as atividades agrícolas, entendem do cultivo da terra, época do plantio", mas também "sabem o que se passa no mundo, assistindo televisão, ouvindo rádio, são carentes de lazer e atrações culturais”.

Os professores consideraram que as crianças e suas famílias são culturalmente marcadas tanto pela forma de vida ${ }^{7}$ do campo quanto pela urbana. Também havia docentes que transitavam entre ambas: constatamos que muitos deles se deslocavam diariamente das pequenas cidades onde residiam para ministrar aulas nas escolas multisseriadas rurais das proximidades, e isso com certeza influencia no planejamento. Uma das supervisoras explicou: "Como a professora é da zona urbana, o planejamento tende a ser bem urbanizado".

As posições dos professores, em certo sentido, escapam da armadilha dos essencialismos e binarismos, que poderia indicar a existência de uma cultura puramente urbana e de outra, puramente camponesa. Suas posições evidenciam claramente um obscurecimento de fronteiras entre as formas de vida urbanas e do campo. Isso corresponde ao que vem sendo discutido por autores como Marques (2002) e Wanderley (2001) a respeito das novas confıgurações que hoje assume o que até então vinha sendo nomeado, dicotomicamente, espaço do campo e espaço urbano, mostrando como ambos os espaços, nos tempos atuais, complexificaram-se em países como o Brasil. Tal complexidade abrange não somente a relação cidade-campo, mas também a não homogeneidade econômica, cultural, social e política de cada um desses espaços e, portanto, a relevância de que isso seja efetivamente contemplado na discussão das formas de vida nas escolas vinculadas ao PEA.

As enunciações dos professores nos permitem dizer que suas escolas estavam situadas

7- Inspiradas na discussão de Veiga-Neto (2003a), optamos por usar a expressão forma de vida no singular, mesmo que estejamos cientes de que seu significado abrange um conjunto diversificado de formas de vida, no plural, que mantêm semelhanças entre si. 
em comunidades que podem ser pensadas como contemplando a complexidade aqui indicada. No entanto, vale mencionar que essa complexidade não abarcou uma dimensão política das formas de vida camponesas do país, como no caso dos conflitos agrários, que são parte de sua constituição.

Contatou-se, ademais, que não só havia um obscurecimento entre as fronteiras do rural e do urbano, mas que tal processo de obscurecimento estava associado a uma hierarquização na qual a cultura urbana era posicionada como superior. Como destacou uma professora, isso se explicitava na forma de vida escolar:

Muitas vezes o professor tenta valorizar [as características culturais] trabalhando com situações locais, o que não é bem visto pelos alunos e muitas vezes pelos pais. Desejam conhecer e "se preparar" para viver na cidade.

Mais ainda, muitas vezes a cultura camponesa era significada como não-cultura. Segundo outra professora, "as crianças têm pouca cultura, buscam na escola a informação, a cultura”. Essa fala indica que a informação e a cultura eram atribuídas à forma de vida urbana, régua a partir da qual a forma de vida camponesa seria medida, avaliada e posicionada como inferior.

Conforme mostramos em outros estudos (KNIJNIK, 2006b; KNIJNIK; WANDERER, 2010), essa hierarquização se consubstancia também no âmbito da educação matemática: os jogos de linguagem matemáticos da forma de vida camponesa, por não coincidirem com os resultados obtidos pelos jogos de linguagem matemáticos transmitidos na escola, são considerados erros. São, portanto, desvalorizados, colocados em uma exterioridade selvagem no que diz respeito à ordem do discurso da matemática escolar. Servindo-nos da perspectiva etnomatemática antes enunciada, podemos inferir sobre os efeitos de verdade envolvidos nesse processo e que funcionam como produto e produtor da marginalização da forma de vida camponesa.
No entanto, ao mesmo tempo em que a forma de vida camponesa era desvalorizada, as narrativas dos professores sobre seus alunos das escolas multisseriadas posicionavam-nos como crianças "ativas", "criativas, alegres, meigas"; "com receptividade imensa”; "carentes, mas com bastante potencial, que até então não foi trabalhado"; que "respeitam o professor e a escola"; "simples, afetivas, educadas"; "tímidas, mas bastante curiosas"; que "trabalham com amplo conhecimento de seu meio"; "religiosas, hospitaleiras, educadas, que se respeitam mutuamente e que gostam de estudar". Narrar as crianças desse modo posicionava-as como alunos exemplares, diferentes dos estudantes urbanos. Essa exemplaridade estava predominantemente marcada por qualidades positivas da ordem do afetivo, do emocional. Assim, tais qualidades acabam por instituir uma forma de vida camponesa e os camponeses que nela vivem são idealizados.

Quando indagados sobre as marcas culturais das comunidades onde atuavam e as possíveis repercussões dessas marcas em sua atividade docente, os professores disseram que as crianças viviam em comunidades predominantemente de colonização alemã ou italiana - mesmo que estivessem presentes famílias "de brasileiros”, isto é, dos que não eram descendentes dos processos de colonização que têm acentuada presença na cultura do Sul do país -, muitas delas falando o "dialeto alemão", trazendo "uma grande bagagem". Portanto, haveria uma diversidade cultural. Tal diversidade era levada em consideração em algumas áreas do currículo: "menos em matemática, mais em estudos sociais”. Assim, podemos pensar que, para os professores, a matemática estaria imune às contingências do social, do político, do cultural. Somente existiria uma única matemática - eurocêntrica, urbana, marcada pelo formalismo e pela abstração - a ser incluída no currículo escolar. Trata-se de uma conclusão bastante plausível, uma vez que a formação dos professores é a mesma e, por isso, haveria semelhanças entre o que é realizado em educação 
matemática nas escolas regulares e nas multisseriadas. 0 estudo empreendido por Schreiber e Knijnik (2011) com professores dos anos iniciais do ensino fundamental graduados em cursos de pedagogia, a partir da perspectiva etnomatemática apresentada neste artigo, fornece elementos para a plausibilidade de tal conclusão.

A ordem do discurso da matemática escolar captura a todos (mesmo que não necessariamente de forma idêntica) e funciona de modo a reificar verdades como as indicadas pelos professores das escolas multisseriadas. É nesse ponto que podemos constatar a produtividade de articular as ideias de Foucault e de Wittgenstein na formulação de nossa perspectiva etnomatemática. Com ela, podemos justificar filosoficamente o que o pensamento etnomatemático vem denominando diferentes etnomatemáticas. Mais ainda, podemos ver as peculiaridades e também as semelhanças de família entre a etnomatemática legitimada como ciência e as outras etnomatemáticas.

0 PEA pode ser pensado como parte dessa estratégia homogeneizadora. Os cadernos endereçados aos alunos instituem essa homogeneização: tanto no que diz respeito ao conteúdo, quanto no que se refere ao modo como este é apresentado (incluindo-se aí as ilustrações). Tais materiais se parecem com os livros didáticos que circulam nas escolas urbanas regulares. A continuada referência aos Parâmetros Curriculares Nacionais, presente no COP e no CEM, é mais um elemento que contribui para a homogeneização. Mesmo que se enfatize que as especificidades culturais, políticas, econômicas e sociais precisam ser garantidas pedagogicamente para que a escola no campo seja também a escola do campo, as condutas dos professores são conduzidas de modo a não contemplar tais especificidades.

No que diz respeito à educação matemática, em especial à área da geometria, a análise do CEM e dos cadernos endereçados aos alunos do PEA mostrou também um tensionamento entre o que é expresso nas orientações pedagógicas e nos materiais didáticos oferecidos aos professores para subsidiar as atividades de sala de aula. 0 exame das orientações pedagógicas permite afırmar que ali é destacada a importância da valorização dos saberes locais da comunidade onde a escola multisseriada se insere, como evidenciam dois dos objetivos para o ensino da matemática:

construir, por meio de interação com o ambiente físico/social, conhecimentos sobre números e seus usos, sistema de numeração e operações numéricas, sobre medidas e sobre geometria; buscar na comunidade, na tradição e nas características do povo do campo subsídios à aprendizagem. (BRASIL, 2010g, p. 10)

Esses objetivos apontam para a relevância de se incluir a geometria entre as práticas pedagógicas da área da matemática, as quais seriam construídas por "meio da interação com o ambiente físico/social”; e tal ambiente, favorecedor da aprendizagem, deveria ser buscado na "tradição e nas características do povo do campo", isto é, na forma de vida da comunidade. A condução do trabalho docente está indicada nas orientações pedagógicas direcionadas aos professores:

A explicitação desses objetivos deixa claro que é intenção dessa coleção conduzir a aprendizagem do aluno a partir das situações numéricas vivenciadas no âmbito do campo, dando-lhe ênfase e valorizando-a; porém, esse é o ponto de partida, pois se almeja que o aluno, conhecendo a matemática praticada em outras realidades, seja capaz de fazer opções e atuar com clareza quando estiver adulto e exercendo uma profissão. (BRASIL, 2010g, p. 10)

A ênfase dada nessas orientações ao uso pedagógico das vivências dos alunos como ponto de partida merece ser analisada. Somos levadas a pensar que se, por um lado, é enfatizada a valorização dos jogos de linguagem da forma de vida da comunidade, por outro lado, há a indi- 
cação de "extrapolar o conhecimento numérico predominante na sua região” (BRASIL, 2010g, p. 10). 0 uso da expressão ponto de partida está associado a essa extrapolação, que acaba por posicionar tais jogos como hierarquicamente inferiores (KNIJNIK, 2004, 2006a).

Nas orientações pedagógicas do PEA para a área da matemática, esses saberes das pessoas - saberes particulares, regionais, locais - são considerados como pontos de partida, como escada para a aprendizagem da matemática "aceita universalmente", reconhecida

como ciência e, como tal, mantenedora de uma organização sistêmica, regida por regras e princípios e uso de padrões que a torna universalizada. (BRASIL, 2010g, p. 10)

Nos cadernos da área de matemática usados pelos educandos, é interessante observar como funciona essa perspectiva evolutiva: no primeiro deles, endereçado aos alunos do $1^{\circ}$ ano, saberes da forma de vida do campo são mencionados, anda que marginalmente (BRASIL, 2010a); no último caderno, endereçado aos alunos do $5^{\circ}$ ano, sequer há alguma menção a outros saberes que não os da matemática escolar (BRASIL, 2010e). Somos levadas a pensar que isso está relacionado à valorização de uma visão platônica marcada pela transcendência - a universalidade e a abstração da matemática - em oposição à perspectiva etnomatemática, que tem como eixo a contingência, os jogos de linguagem matemáticos praticados no solo áspero. Seguindo Wittgenstein, "é preciso voltar ao atrito do solo áspero (I.F. §107) ${ }^{8}$ das práticas sociais e aí estabelecer os critérios de nossa racionalidade" (CONDÉ, 2004, p. 29).

É importante, ademais, problematizar, no material de pesquisa, o valor atribuído à incorporação de práticas não escolares no currículo. O CEM, ao propor a valorização dos saberes locais, carrega consigo uma das ideias que está no cerne da etnomatemática (KNIJNIK, 2010),

8- 0 autor (CONDÉ, 2004) está referindo-se ao aforismo 107 do livro Investigações filosóficas, de Wittgenstein. mesmo que essa vertente da educação matemática não seja ali mencionada: o pensamento etnomatemático considera haver a possibilidade de incorporar, em estado puro, práticas matemáticas de fora da escola no currículo escolar. Servindo-nos das formulações wittgensteinianas, afırmamos que tal operação de traslado é inviável. Não há como trasladar jogos de linguagem produzidos em uma forma de vida para outra sem que tais jogos sejam capturados pela forma de vida de chegada. Em suma, as práticas matemáticas na escola são, de fato, práticas matemáticas $d a$ escola. A partir da simplificação de uma relação bastante complexa (a relação entre saberes de dentro e de fora da escola), somos levados a pensar que as diretrizes dadas aos professores por meio do CEM funcionam como uma estratégia que opera sobre os sujeitos da educação envolvidos no PEA, levando-os a trivializar a necessidade de teorização para informar os processos educativos.

Por sua vez, ao se analisarem os cadernos da área de matemática endereçados aos alunos do PEA, no que diz respeito à geometria, constata-se que as atividades propostas não contemplam "tradição e características do povo do campo", como indicado nas mencionadas orientações para os educadores. Por exemplo, são abordadas as medidas de massa, comprimento e capacidade por meio de unidades como quilograma, metro e litro, respectivamente, isto é, as unidades padrão do sistema métrico decimal, imposto no país a partir de 1873 (SANTOS, 2005). Como discutido em outro estudo (KNIJNIK; OLIVEIRA, 2011), realizado no interior do Estado do Rio Grande do Sul, tal imposição produziu movimentos de resistência e contraconduta, no sentido atribuído por Foucault a essas expressões: movimentos de resistência, como a Revolta dos Quebra-Quilos, e movimentos de contraconduta, identificados nas certidões de registro de imóveis da localidade no período. Em tais certidões eram usadas tanto unidades oficiais de medidas, quanto aquelas próprias da forma de vida rural da época, ainda hoje presentes nas práticas laborais da comunidade. 
Com base nesse estudo e em outros desenvolvidos em diferentes espaços rurais $\backslash$ do campo no país a partir da mesma perspectiva etnomatemática - tais como o trabalho de Santos (2005) -, podemos afirmar que jogos de linguagem matemáticos envolvendo unidades não oficiais de medida seguem sendo praticados. No entanto, os cadernos do PEA para os alunos escassamente se referem a tais jogos, reforçando a posição privilegiada que usualmente as medidas-padrão têm na matemática escolar. Quando isso ocorre, as atividades que propõem a medição com o uso de unidades não ofıciais - tais como o palmo - são orientadas no sentido de que os alunos concluam que essas não são as melhores unidades a serem adotadas, uma vez que, diferentemente do sistema métrico decimal, elas carregariam consigo uma imprecisão. Assim, devido a essa imprecisão, tais unidades de medida deveriam ser utilizadas apenas como ponto de partida para a aquisição das unidades-padrão. A perspectiva etnomatemática que embasa este estudo problematiza exatamente esse aspecto.

Além disso, consideramos haver um tensionamento entre as orientações pedagógicas dadas aos professores e as atividades propostas para os alunos do PEA. O CEM (BRASIL, 2010g, p. 9) enfatiza que "é importante atentar para que não aconteça a desvalorização dos saberes identificados com a comunidade", e que é preciso desconstruir a ideia de que as crianças nada sabem de matemática: "Nas suas brincadeiras e vivências diárias, elas vão adquirindo muitas informações e construindo conhecimentos matemáticos informais” (p. 18). Assim,

ao chegar à escola, a criança já possui muitas noções matemáticas incipientes, incompletas e informais. Cabe ao professor verificar quais e que tipo de experiências ela tem e a partir delas planejar e iniciar seu trabalho. (p. 11)

Porém, os materiais pedagógicos disponibilizados aos alunos evidenciam, sobretudo, jogos de linguagem matemáticos próprios da forma de vida escolar, cuja gramática é marcada pela abstração e pelo formalismo (KNIJNIK; WANDERER, 2010).

\section{Considerações finais}

A perspectiva etnomatemática que embasou o exercício analítico apresentado neste artigo ofereceu ferramentas teóricas que possibilitaram examinar o PEA como uma política pública que, de diferentes modos, conduz a conduta dos professores, dos alunos e, de modo mais amplo, da população do campo, contribuindo para constituir seus modos de dar sentido à escola, ao aprender e ao ensinar, particularmente, a matemática. Essa perspectiva permite problematizar também a geração de dicotomias entre as diversas linguagens matemáticas, rompendo com as distinções entre alta cultura - aqui entendida como a matemática acadêmica - e baixa cultura - as outras linguagens matemáticas, tais como a matemática camponesa do Movimento Sem Terra (KNIJNIK, 2006a).

Foi também de especial serventia o uso da noção foucaultiana de governamentalidade. Operando com essa ferramenta teórica, a análise dos documentos do PEA e dos questionários nos fez concluir que o programa conduz a conduta da população camponesa. Ao regular essa população, ele funciona como um dispositivo biopolítico que acaba por posicionar sua forma de vida - seus valores, seus saberes, seus modos de dar sentido ao mundo - em um patamar inferior ao da forma de vida urbana. Examinando o material de pesquisa, em especial no que se refere ao ensinar e aprender geometria, evidenciamos as estratégias que são postas em ação pelo PEA, de modo a reforçar esse processo hierarquizante que é, no limite, um processo de construção de desigualdades. Assim, a população urbana e a do campo acabam sendo significadas não apenas como diferentes, mas como desiguais.

Neste texto, detivemo-nos a analisar alguns elementos de uma política pública 
endereçada à população do campo. Mesmo que, como mencionado, tenhamos nos detido na discussão de um dos dois eixos que compõem o cenário da governamentalidade discutido por Foucault (CASTR0, 2009), estamos cientes de que não há uma linha divisória entre ambos. Nesse sentido, é importante destacar que, ao escrutinar o material de pesquisa, reunimos elementos empíricos que nos permitirão mostrar, em outro momento, como o PEA atua também no que diz respeito ao governo de si. Assim será possível adentrar o âmbito das discussões sobre a ética formuladas pelo filósofo francês.

\section{Referências}

ARAGÃO, Márcia Cristina da Cruz. A educação do campo e o Programa Escola Ativa: uma análise do Programa em escolas sergipanas. Dissertação (Mestrado em Educação) - Universidade Federal de Sergipe, São Cristóvão, 2011.

BILBA, Corneliu. Après Wittgenstein: langage, pouvoir et stratégie chez Foucault. In: GROS, Frédéric; DAVIDSON, Arnold. Foucault, Wittgenstein: de possibles rencontres. Paris: Éditions Kimé, 2011. p. 117-156.

BRASIL, Ministério da Educação. Secretaria de Educação Continuada, Alfabetização e Diversidade. Caderno de ensino e aprendizagem: matemática 1 (Programa Escola Ativa). 2. ed. Brasília: SECAD/MEC, 2010a.

Caderno de ensino e aprendizagem: matemática 2 (Programa Escola Ativa). 2. ed. Brasília: SECAD/MEC, 2010b.

Caderno de ensino e aprendizagem: matemática 3 (Programa Escola Ativa). 2. ed. Brasília: SECAD/MEC, 2010c.

Caderno de ensino e aprendizagem: matemática 4 (Programa Escola Ativa). 2. ed. Brasília: SECAD/MEC, 2010d.

Caderno de ensino e aprendizagem: matemática 5 (Programa Escola Ativa). 2. ed. Brasília: SECAD/MEC, 2010e.

Caderno de orientações pedagógicas para formação de educadoras e educadores (Programa Escola Ativa). Brasilia: SECAD/MEC, 2010f.

Caderno do educador: matemática (Programa Escola Ativa). Brasília: SECAD/MEC, 2010g.

Projeto base (Programa Escola Ativa). 2. ed. Brasília: SECAD/MEC, 2010h.

BUJES, Maria Isabel Edelweiss. Manuais pedagógicos e formação docente: elos de poder/saber. Currículo sem fronteiras, v. 9, n. 1, p. 267-288, 2009.

CASTRO, Edgardo. Vocabulário de Foucault. Belo Horizonte: Autêntica, 2009.

CONDÉ, Mauro Lúcio Leitão. As teias da razão: Wittgenstein e a crise da racionalidade moderna. Belo Horizonte: Argvmentum Editora, 2004.

CONRADO, Andréia Lunkes. A pesquisa brasileira em etnomatemática: desenvolvimento, perspectivas, desafios. Dissertação (Mestrado em Educação) - Faculdade de Educação, Universidade de São Paulo, São Paulo, 2005.

D’AGOSTINI, Adriana et al. Nota técnica sobre o Programa Escola Ativa: uma análise crítica. Fórum Nacional de Educação do Campo (FONEC), 2011.

D’AMBROSIO, Ubiratan. Etnomatemática. São Paulo: Ática, 1990. 
Etnomatemática e educação. In: KNIJNIK, Gelsa; WANDERER, Fernanda; OLIVEIRA, Cláudio José de (Orgs.). Etnomatemática, currículo e formação de professores. Santa Cruz do Sul: EDUNISC, 2004. p. 39-52.

DUARTE, Cláudia Glavam. A "realidade" nas tramas discursivas da educação matemática escolar. Tese (Doutorado em Educação) - Universidade do Vale do Rio dos Sinos, São Leopoldo, 2009.

FIMYAR, Olena. Governamentalidade como ferramenta conceitual na pesquisa de políticas educacionais. Educação \& Realidade, Porto Alegre, v. 34, n. 2, p. 35-56, 2009.

FOUCAULT, Michel. Microfísica do poder. Rio de Janeiro: Edições Graal, 2003.

Segurança, território, população. São Paulo: Martins Fontes, 2008.

GADELHA, Sylvio. Biopolítica, governamentalidade e educação: introdução e conexões, a partir de Michel Foucault. Belo Horizonte: Autêntica, 2009.

GONÇALVES, Gustavo B. B. Programa Escola Ativa: educação do campo e trabalho docente. Tese (Doutorado em Políticas Públicas e Formação Humana) - Universidade do Estado do Rio de Janeiro, Rio de Janeiro, 2009.

GROS, Frédéric; DAVIDSON, Arnold. Foucault, Wittgenstein: de possibles rencontres. Paris: Éditions Kimé, 2011.

JOSEPH, George Gheverghese. La Cresta Del Pavo Real: las matemáticas y sus raíces no europeas. Madrid: Ediciones Pirámide, 1996.

KNIJNIK, Gelsa. Currículo, cultura e saberes na educação matemática de jovens e adultos: um estudo sobre a matemática oral camponesa. In: SEMINÁRIO DE PESQUISA EM EDUCAÇÃO DA REGIÃO SUL, 5., 2004, Curitiba. Anais... Curitiba: Pontifícia Universidade Católica do Paraná, 2004.

. Educação matemática, culturas e conhecimento na luta pela terra. Santa Cruz do Sul: EDUNISC, 2006a.

. Itinerários da etnomatemática: questões e desafios sobre o cultural, o social e o político na educação matemática. In: KNIJNIK, Gelsa; WANDERER, Fernanda; OLIVEIRA, Cláudio Jose (Orgs.). Etnomatemática, currículo e formação de professores. Santa Cruz do Sul: EDUNISC, 2006b. p. 19-38.

Uma discussão de dez minutos entre dois grandes filósofos: atiçando nosso trabalho de pensar. Educação Unisinos, São Paulo, v. 13, p. 84-86, 2009.

. Educação matemática, currículo e diferença cultural. In: LOPES, Maura; FABRIS, Eli (Orgs.). Aprendizagem \& inclusão: implicações curriculares. Santa Cruz do Sul: EDUNISC, 2010. p. 51-68.

Wittgenstein y las matemáticas en la forma de vida de los campesinos Sin Tierra de Brasil. Perspectivas Metodológicas, v. 11, p. 36-48, 2011.

- Differentially positioned language games: ethnomathematics from a philosophical perspective. Educational Studies in Mathematics, v. 80, p. 87-100, 2012.

KNIJNIK, Gelsa; OLIVEIRA, Sabrina. Educação matemática e jogos de linguagem da forma de vida rural do município de Santo Antonio da Patrulha: um estudo sobre o medir a terra e suas unidades de medida. Boletim GEPEM, Rio de Janeiro, v. 59, p. 62-72, 2011.

KNIJNIK, Gelsa; WANDERER, Fernanda. Mathematics education and differential inclusion: a study about two Brazilian time-space forms of life. ZDM (Berlin Print), v. 42, p. 349-361, 2010.

KOLLING, Edgar Jorge; NERY, Irmão; MOLINA, Monica Castagna (Orgs.). Por uma educação básica do campo. Brasilia: UnB, 1999.

LIZCANO, Emmanuel. Metáforas que nos piensan: sobre ciência, democracia y otras poderosas ficciones. Madrid: Ediciones Bajo Cero, 2006.

MARQUES, Marta I. M. 0 conceito de espaço rural em questão. Revista Terra Livre, São Paulo, ano 18, n. 19, p. 95-112, 2002. 
MATOS, Cleide Carvalho de. Concepções, princípios e organização do currículo no Projeto Escola Ativa. Dissertação (Mestrado em Educação) - Universidade Federal do Pará, Belém, 2010.

MIGUEL, Antonio; VILELA, Denise Silva. Práticas escolares de mobilização de cultura matemática. Cadernos Cedes, Campinas, v. 28, n. 74, p. 97-120, 2008.

PALTRINIERI, Luca. Pratique et langage chez Wittgenstein et Foucault. In: GROS, Frédéric; DAVIDSON, Arnold. Foucault, Wittgenstein: de possibles rencontres. Paris: Éditions Kimé, 2011. p. 41-78.

PINXTEN, Rik; FRANCOIS, Karen. Politics in an Indian canyon? Some thoughts on the implications of ethnomathematics. Educational Studies in Mathematics, v. 78, n. 2, p. 261-273, 2011.

RIBEIRO, José Pedro Machado; DOMITE, Maria do Carmo Santos; FERREIRA, Rogério (Orgs.). Etnomatemática: papel, valor e significado. São Paulo: Zouk, 2004.

SANTOS, Marilene. Práticas sociais produtivas e unidades de medidas em assentamentos do nordeste sergipano. Dissertação (Mestrado em Educação) - Universidade do Vale do Rio dos Sinos, São Leopoldo, 2005.

SARAIVA, Karla; SANTOS, lolanda M. (Orgs.). Educação contemporânea \& artes de governar. Canoas: Ed. ULBRA, 2010.

SCHREIBER, Juliana; KNIJNIK, Gelsa. Educação matemática e formação de professores dos anos iniciais do ensino fundamental. In: CONGRESSO INTERAMERICANO DE EDUCAÇÃO MATEMÁTICA, 13., 2011, Recife. Anais... Recife: Editora da UFPE, 2011.

SILVA, Roberto Rafael Dias. A constituição da docência no ensino médio no Brasil contemporâneo: uma analítica de governo. Tese (Doutorado em Educação) - Universidade do Vale do Rio dos Sinos, São Leopoldo, 2011.

VEIGA-NETO, Alfredo. Cultura, culturas e educação. Revista Brasileira de Educação, Rio de Janeiro, v. 23, p. 5-15, 2003a.

Foucault \& a Educação. Belo Horizonte: Autêntica, 2003b. 2006. p. 79-91.

Na oficina de Foucault. In: KOHAN, Walter Omar; GONDRA, José (Orgs.). Foucault 80 anos. Belo Horizonte: Autêntica,

VEIGA-NETO, Alfredo; LOPES, Maura C. Há teoria e método em Michel Foucault? Implicações educacionais. In: CLARETO, Sônia; FERRARI, Anderson (Orgs.). Foucault, Deleuze e educação. Juiz de Fora: Ed. UFJF, 2010. p. 33-47.

WALKERDINE, Valerie. 0 raciocínio em tempos pós-modernos. Educação e Realidade, São Paulo, v. 20, n. 2, p. 207-226, 1995.

WANDERLEY, Maria Nazareth. A ruralidade no Brasil moderno: por um pacto social pelo desenvolvimento rural. In: GIARRACCA, Norma (Org.). Una nueva ruralidad en America Latina? Buenos Aires: Clocso, 2001. p. 31-44.

WITTGENSTEIN, Ludwig. Investigações filosóficas. Petrópolis: Vozes, 2004.

Recebido em: 26.06.2012

Aprovado em: 13.09.2012

Gelsa Knijnik é doutora em Educação, professora do Programa de Pós-Graduação em Educação da Universidade do Vale do Rio dos Sinos (UNISINOS), pesquisadora do Conselho Nacional de Desenvolvimento Científico e Tecnológico (CNPQ) e coordenadora do Grupo Interinstitucional de Pesquisa em Educação Matemática e Sociedade (GIPEMS).

Fernanda Wanderer é doutora em Educação e professora da Faculdade de Educação da Universidade Federal do Rio Grande do Sul (UFRGS). Integra o Grupo Interinstitucional de Pesquisa em Educação Matemática e Sociedade (GIPEMS) e realiza pesquisas na área da educação matemática, tendo como referencial teórico a etnomatemática. 